\title{
Optimization of the composition of fly ash cement by simulation
}

\author{
Yutaka AIKAWA ${ }^{1, \dagger}$, Norrarat SIRIBUDHAIWAN ${ }^{1}$, Shigeyoshi MIYAHARA ${ }^{2}$ and Etsuo SAKAI ${ }^{1}$ \\ ${ }^{1}$ Department of Materials Science and Engineering, School of Materials and Chemical Technology, Tokyo Institute of Technology, \\ 2-12-1 Ookayama, Meguro-ku, Tokyo 152-8552, Japan \\ ${ }^{2}$ Technology Center, Civil Engineering Research Institute, Taisei Corporation, \\ 344-1 Nase-cho, Totsuka-ku, Yokohama 245-0051, Japan
}

In order to estimate the upper limit of fly ash as an additive to fly ash cement, the dependence of the hydration reaction of fly ash cement on two parameters, i.e., the fly ash particle size and $C_{3} S$ quantity, were evaluated based on theoretical simulation. In the early stage of the hydration reaction, the reaction ratio was largely independent of the fly ash particle size; however, the reaction ratio became remarkably dependent on the fly ash particle size during the stage from three weeks to one year. Because controlling the fly ash particle size is inexpedient in industry, only the quantity of fly ash required for fly ash cement to achieve properties similar to those of ordinary Portland cement was simulated by regulating the quantity of $\mathrm{C}_{3} \mathrm{~S}$. It was found based on the simulations that fly ash cement containing $20 \%$ fly ash in high alite cement containing $67 \% \mathrm{C}_{3} \mathrm{~S}$ was adequate, and this result was confirmed by empirical evaluation.

(C2018 The Ceramic Society of Japan. All rights reserved.

Key-words : Fly ash, Ordinary portland cement, Size distribution, Hydration reaction, Rate of reaction, Reaction ratio, Pozzolanic reaction, Porosity

[Received September 27, 2017; Accepted January 9, 2018]

\section{Introduction}

The addition of fly ash to cement is a practical method for reusing the coal ash produced by coal-fired power plants in Japan, where coal ash production reaches approximately 10 million tons per year. ${ }^{1)}$ The resulting fly ash cement exhibits improved fluidity as one of its main advantages.

We previously reported that the porosity of fly ash concrete increases as the quantity of fly ash added increases. $^{2), 3)}$ It has been reported, however, that the strength of concrete is by nature inversely proportional to its porosity. ${ }^{4)}$ There is therefore a tendency for the strength of concrete to decrease as the ratio of fly ash increases.

It is thus of practical importance to determine the upper limit of fly ash content at which the strength is equivalent to that of common cement concrete. To date, the upper limit of fly ash that can be added has been determined by trial and error in the use of fly ash cement as a substitute for ordinary cement; this limit has not been quantified, however, via simulations considering the ratio of the components (compositional ratio) and the particle size distribution. In this study, we quantitatively evaluate the optimum fly ash content as a cement additive by simulation instead of by the conventional method.

\section{Theoretical consideration}

Tomosawa's equation for analysis of the hydration reaction of cement is as follows: ${ }^{.5}$

\footnotetext{
Corresponding author: Y. Aikawa; E-mail: aikawa.y.ac@ m.titech.ac.jp
}

$$
\begin{aligned}
& -\frac{\mathrm{d} \alpha\left(r_{0}, t\right)}{\mathrm{d} t}=\frac{3 C_{\mathrm{w} \infty}}{v \rho_{\mathrm{C}} r_{0}^{2}} \\
& \times \frac{1}{\frac{1}{r_{0} \alpha\left(r_{0}, t\right)^{2 / 3}}\left(\frac{1}{k_{\mathrm{d}}}+\frac{1}{k_{\mathrm{r}}}\right)+\frac{\alpha\left(r_{0}, t\right)^{-1 / 3}-\left[2-\alpha\left(r_{0}, t\right)\right]^{-1 / 3}}{D_{\mathrm{e}}}}
\end{aligned}
$$

where, $-\mathrm{d} \alpha / \mathrm{d} t$ is the rate of reaction, $\alpha$ is the residual fraction $\left(1-\alpha\right.$ is the degree of reaction), $r_{0}$ is the particle radius, $C_{\mathrm{w} \infty}$ is the concentration of water around the particle, $v$ is the ratio of stoichiometry in the water-cement reaction, $\rho_{\mathrm{C}}$ is the density of the cement, $k_{\mathrm{r}}$ is the coefficient of the velocity of the reaction, and $k_{\mathrm{d}}$ is the coefficient of the mass transfer. The latter is written as a function of $\alpha$, as given by Eq. (2):

$$
k_{\mathrm{d}}=\frac{B_{\mathrm{d}}}{1-\alpha}+C_{\mathrm{d}}(1-\alpha)^{2}
$$

where $B_{\mathrm{d}}$ is the coefficient describing the formation of a protective layer that permits diffusion, and $C_{\mathrm{d}}$ is the coefficient expressing the destruction of the protective layer. The effective diffusion coefficient $D_{\mathrm{e}}$ is written as a function of $\alpha$ :

$$
D_{\mathrm{e}}=D_{\mathrm{E}}\left[\ln \frac{1}{1-\alpha}\right]^{2} .
$$

The reaction rate of a cement particle system with respect to a size distribution is given by ${ }^{6}$

$$
-\frac{\mathrm{d} \alpha}{\mathrm{d} t}=-f\left(r_{i}\right) \frac{\mathrm{d} \alpha\left(r_{i}, t\right)}{\mathrm{d} t}
$$


where $r_{i}$ is the radius of the $i$-th particle, and $f\left(r_{i}\right)$ is normalized as

$$
\sum_{i} f\left(r_{i}\right)=1
$$

It is assumed that the hydration reaction of ordinary Portland cement (OPC) is a linear combination the hydration reactions of each component $\left(\mathrm{C}_{3} \mathrm{~S}, \mathrm{C}_{2} \mathrm{~S}, \mathrm{C}_{3} \mathrm{~A}, \mathrm{C}_{4} \mathrm{AF}\right)$ as:

$$
\begin{aligned}
-\frac{\mathrm{d} \alpha_{\mathrm{OPC}}}{\mathrm{d} t}= & -\frac{1}{\sum_{i} \frac{m_{i}}{\rho_{i}}} \sum_{i} \frac{m_{i}}{\rho_{i}} \frac{\mathrm{d} \alpha_{i}}{\mathrm{~d} t} \\
& \left(i=\mathrm{C}_{3} \mathrm{~S}, \mathrm{C}_{2} \mathrm{~S}, \mathrm{C}_{3} \mathrm{~A}, \mathrm{C}_{4} \mathrm{AF}\right)
\end{aligned}
$$

where $m_{i}$ and $\rho_{i}$ are the mass and density of component $i$, respectively. Equation (6) is an adequate approximation if the interactions among components during the hydration reaction can be eliminated, and hydration of OPC can thus be simulated while varying the ratio of components at the start of the reaction. The reaction ratio of each component changes in accordance with the ratio of fly ash incorporated into fly ash cement.

On the other hand, the pozzolanic reaction of fly ash in fly ash cement has also been simulated based on Eq. (1), as described in Reference. ${ }^{3)}$ The reaction ratio of fly ash changes in accordance with the ratio of fly ash incorporated into fly ash cement.

The porosity $(\Delta)$ of the fly ash cement at time $t$ is expressed as: ${ }^{3)}$

$$
\begin{aligned}
& \Delta=\delta^{\prime} \\
& -\frac{1-\delta^{\prime}}{1+\frac{\rho_{\mathrm{C}}}{\rho_{\mathrm{A}}} \frac{M_{\mathrm{A}}}{M_{\mathrm{C}}}}\left\{\left(n_{\mathrm{C}}-1\right) \frac{\sum_{i=1}^{N_{\mathrm{C}}} f_{\mathrm{C}}\left(r_{i(\mathrm{C})}\right) r_{i(\mathrm{C})}^{3}\left[1-\alpha_{\mathrm{C}}\left(r_{i(\mathrm{C})}, t\right)\right]}{\sum_{i=1}^{N_{\mathrm{C}}} f_{\mathrm{C}}\left(r_{i(\mathrm{C})}\right) r_{i(\mathrm{C})}^{3}}\right. \\
& \left.+\frac{\rho_{\mathrm{C}}}{\rho_{\mathrm{A}}} \frac{M_{\mathrm{A}}}{M_{\mathrm{C}}}\left(n_{\mathrm{A}}-1\right) \frac{\sum_{i=1}^{N_{\mathrm{A}}} f_{\mathrm{A}}\left(r_{i(\mathrm{~A})}\right) r_{i(\mathrm{~A})}^{3}\left[1-\alpha_{\mathrm{A}}\left(r_{i(\mathrm{~A})}, t\right)\right]}{\sum_{i=1}^{N_{\mathrm{A}}} f_{\mathrm{A}}\left(r_{i(\mathrm{~A})}\right) r_{i(\mathrm{~A})}^{3}}\right\}
\end{aligned}
$$

Equation (7) is applied to fly ash cement when the respective reaction ratios of OPC (subscript $C$ ) and fly ash (subscript A) in fly ash cement can be measured.

In cases where in which only the reaction ratio of the fly ash cement is given, the following expression is used for calculation of porosity. ${ }^{6}$

$$
\Delta=\delta^{\prime}-\left(1-\delta^{\prime}\right)(n-1) \frac{\sum_{i=1}^{N} f\left(r_{i}\right) r_{i}^{3}(1-\alpha)}{\sum_{i=1}^{N} f\left(r_{i}\right) r_{i}^{3}}
$$

where $f\left(r_{i}\right)$ is the particle size distribution as the linear combination of OPC and fly ash, as defined in the following expression:

$$
\begin{aligned}
f\left(r_{i}\right)= & {\left[\frac{m_{\mathrm{C}} f_{\mathrm{C}}\left(r_{i}\right)}{\rho_{\mathrm{C}} \sum_{i=1}^{N_{\mathrm{C}}} f_{\mathrm{C}}\left(r_{i}\right) r_{i}^{3}}+\frac{m_{\mathrm{A}} f_{\mathrm{A}}\left(r_{i}\right)}{\rho_{\mathrm{A}} \sum_{i=1}^{N_{\mathrm{A}}} f_{\mathrm{A}}\left(r_{i}\right) r_{i}^{3}}\right] } \\
& /\left[\frac{m_{\mathrm{C}}}{\rho_{\mathrm{C}} \sum_{i=1}^{N_{\mathrm{C}}} f_{\mathrm{C}}\left(r_{i}\right) r_{i}^{3}}+\frac{m_{\mathrm{A}}}{\rho_{\mathrm{A}} \sum_{i=1}^{N_{\mathrm{A}}} f_{\mathrm{A}}\left(r_{i}\right) r_{i}^{3}}\right]
\end{aligned}
$$

\section{Simulation of hydration reactions}

Increasing the content of $\mathrm{C}_{3} \mathrm{~S}$ and decreasing the average particle size of the added fly ash are considered as methods for achieving fly ash cement characteristics that are comparable to those of ordinary cement. Given that it has already been determined that the hydration reaction of OPC in fly ash cement can be represented as a linear combination of the hydration reactions of the components $\left(\mathrm{C}_{3} \mathrm{~S}, \mathrm{C}_{2} \mathrm{~S}, \mathrm{C}_{3} \mathrm{~A}, \mathrm{C}_{4} \mathrm{AF}\right)$, and that the binding constants depend on the compositional ratio, ${ }^{3)}$ it is possible to simulate the characteristics of hydration reactions for arbitrary compositions of OPC in fly ash cement.

\subsection{Simulation of hydration reactions with various ratios of $\mathrm{C}_{3} \mathrm{~S}$ and $\mathrm{C}_{2} \mathrm{~S}$ in fly ash cement}

Table 1 shows the composition of samples with various ratios of $\mathrm{C}_{3} \mathrm{~S}$ and $\mathrm{C}_{2} \mathrm{~S}$ used in the simulation. When the gross weight of the $\mathrm{C}_{3} \mathrm{~S}+\mathrm{C}_{2} \mathrm{~S}$ in fly ash cement is constant, regardless of the $\mathrm{C}_{3} \mathrm{~S} / \mathrm{C}_{2} \mathrm{~S}$ ratio, the pozzolanic reaction of the fly ash will proceed. The main reasons for this are as follows: up until the 28-day point, about $95 \%$ of the fly ash remains unreacted, unlike the $\mathrm{C}_{3} \mathrm{~S}$, which reacts rapidly; beyond the 28-day point, the $\mathrm{C}_{2} \mathrm{~S}$ contributes to the fly ash reaction, because the $\mathrm{C}_{2} \mathrm{~S}$ reaction proceeds gradually. $\left.{ }^{3}\right)$ Thus, the $\mathrm{Ca}(\mathrm{OH})_{2}$ necessary for the pozzolanic reaction of the fly ash is supplied by both the $\mathrm{C}_{3} \mathrm{~S}$ and $\mathrm{C}_{2} \mathrm{~S}$. Table 2 shows the composition of the fly ash $(76.6 \%$ vitrification ratio) used in this simulation. It is supposed that the fly ash cement is made by adding $20 \%$ fly ash (76.6\% vitrification ratio) to each OPC sample in Table 1. The hydration reaction of fly ash cement sample No. 4 was already calculated in a previous study, ${ }^{3}$ ) which corresponds to $\mathrm{C}_{3} \mathrm{~S} 55.8 \%$ in Fig. 1. Similarly, the simula-

Table 1. Composition of each sample type when the gross weight of $\mathrm{C}_{3} \mathrm{~S}+\mathrm{C}_{2} \mathrm{~S}$ is constant

\begin{tabular}{lccccc}
\hline & $\mathrm{C}_{3} \mathrm{~S}$ & $\mathrm{C}_{2} \mathrm{~S}$ & $\mathrm{C}_{3} \mathrm{~A}$ & $\mathrm{C}_{4} \mathrm{AF}$ & $\mathrm{CaSO}_{4}$ \\
\hline No. 1 & 40.0 & 36.7 & 8.30 & 8.90 & 3.49 \\
No. 2 & 45.0 & 31.7 & 8.30 & 8.90 & 3.49 \\
No. 3 & 50.0 & 26.7 & 8.30 & 8.90 & 3.49 \\
No. 4 & 55.8 & 20.9 & 8.30 & 8.90 & 3.49 \\
No. 5 & 60.0 & 16.7 & 8.30 & 8.90 & 3.49 \\
No. 6 & 65.0 & 11.7 & 8.30 & 8.90 & 3.49 \\
No. 7 & 70.0 & 6.70 & 8.30 & 8.90 & 3.49 \\
\hline
\end{tabular}

Table 2. Composition of fly ash with a $76.6 \%$ glass phase

\begin{tabular}{cccccc}
\hline & $\alpha$-Quartz & Mullite & Magnetite & $\mathrm{CaSO}_{4}$ & Glass phase \\
\hline FA76.6 & 8.70 & 12.4 & 0.40 & 0.70 & 76.6 \\
\hline
\end{tabular}




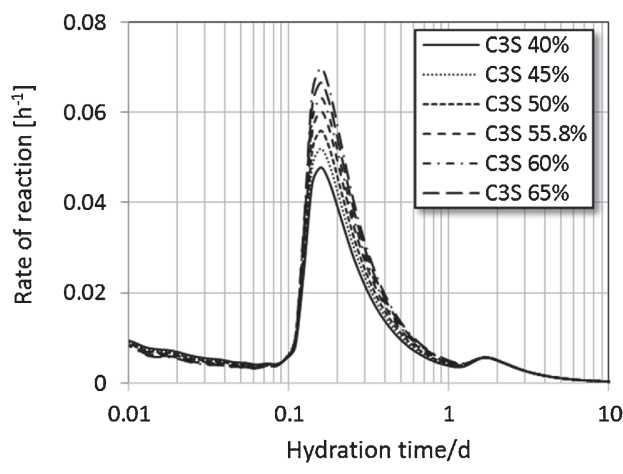

(a)

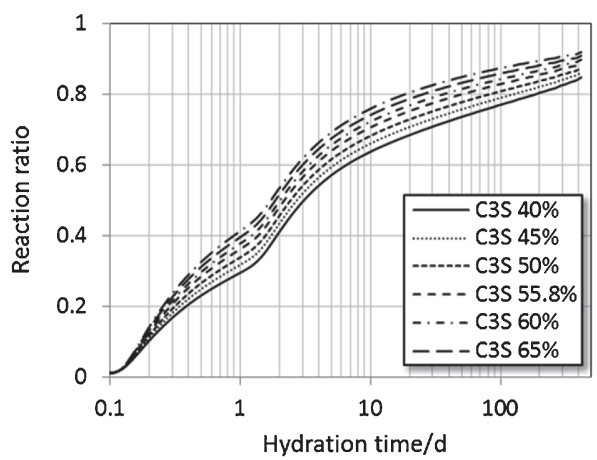

(b)

Fig. 1. Simulated results for (a) the rate of reaction and (b) the reaction ratio of fly ash cements made by adding $20 \%$ fly ash to the samples in Table 1.

tion results for the hydration reactions of the other fly ash cement samples are shown in Fig. 1. The reaction ratio of the fly ash cement, including the standard composition of No. $4\left(\mathrm{C}_{3} \mathrm{~S} 55.8 \%\right)$, increased gradually with increases in the $\mathrm{C}_{3} \mathrm{~S}$ content. The hydration reaction ratio of the fly ash cement samples did not vary significantly over time from $1 \mathrm{~d}$ to $1 \mathrm{y}$, based on the quantity of $\mathrm{C}_{3} \mathrm{~S}$, as shown in Fig. 1(b).

\subsection{Simulation of hydration reactions by varying the average particle size of fly ash in fly ash cement}

To address the issue of varying average particle sizes of fly ash, the particle size distribution of fly ash was treated as a constant in a log-normality graph. The average particle sizes obtained by sifting the fly ash particle size distribution are shown in Fig. 2. Figure 3 shows simulation results for the hydration reaction, i.e., (a) the rate of reaction and (b) the reaction ratio for fly ash $(76.6 \%$ vitrification ratio), calculated based on variation of the average particle radius $\langle r\rangle$. A tendency for the reaction ratio to increase with decreases in $\langle r\rangle$ is clearly observed. This phenomenon indicates that the fine particle effect in the pozzolanic reaction is remarkable. The reaction ratio changes minimally in the initial seven days, after which the rate of change increases rapidly.

The effect of the average particle size of fly ash on the reaction ratio follows a trend that is clearly different from the effect of the $\mathrm{C}_{3} \mathrm{~S}$ content in OPC on the reaction ratio.

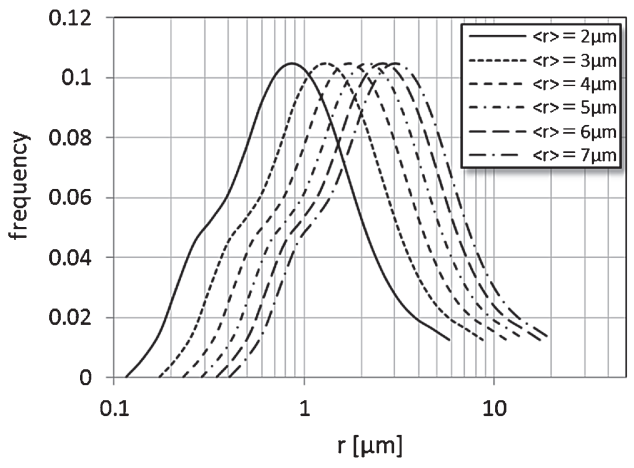

Fig. 2. Particle size distribution of fly ash used in the simulation.

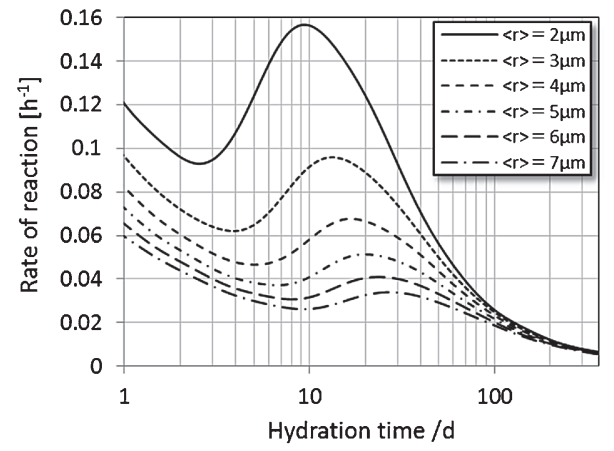

(a)

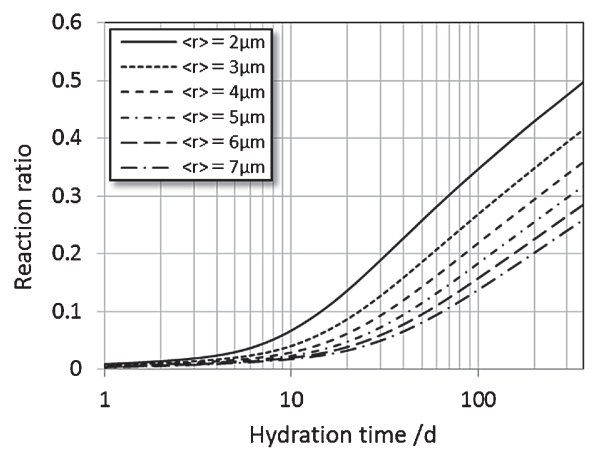

(b)

Fig. 3. Simulated results for (a) the rate of reaction and (b) the reaction ratio of samples with various particle size distributions of fly ash.

The variations in the calculated reaction ratio of fly ash cement (fly ash $20 \%$ cement) when the quantity of $\mathrm{C}_{3} \mathrm{~S}$ in OPC and the mean radius $\langle r\rangle$ of fly ash are taken as the vertical axis and the horizontal axis, respectively, are shown in Fig. 4. The reaction ratio tends to increase when the particle size of fly ash is smaller and the quantity of $\mathrm{C}_{3} \mathrm{~S}$ is higher. After $28 \mathrm{~d}$, this tendency becomes remarkable. In the initial seven days, however, the reaction ratio exhibits little dependence on the fly ash particle size, and depends instead mainly on the quantity of $\mathrm{C}_{3} \mathrm{~S}$.

\section{Experimental results}

Controlling the particle size of fly ash requires classifying the fly ash powder into several particle sizes. When it comes to practical applications in industry, however, separation of fly ash into various particle sizes is an expensive 


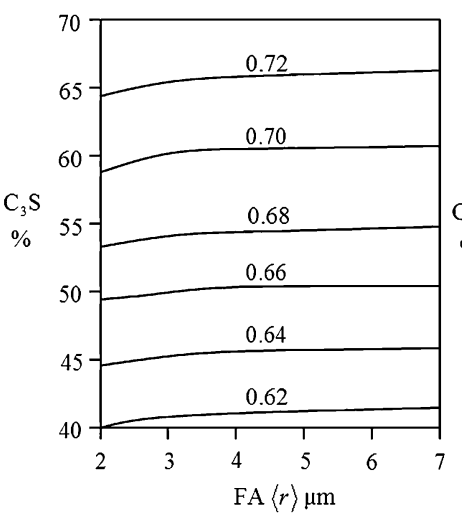

(a)

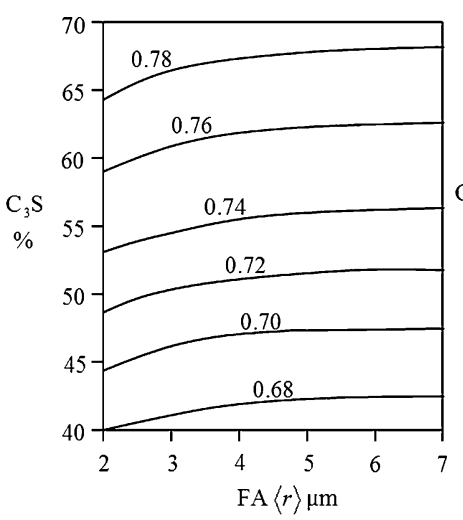

(b)

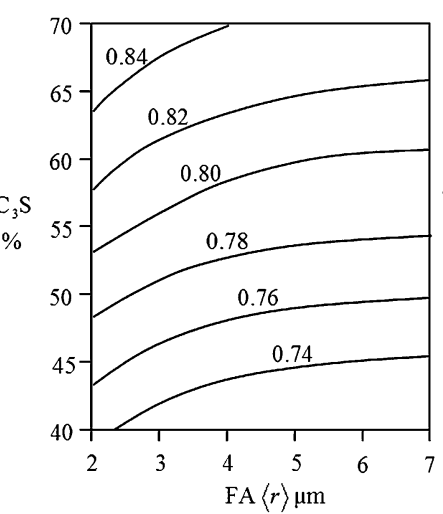

(c)

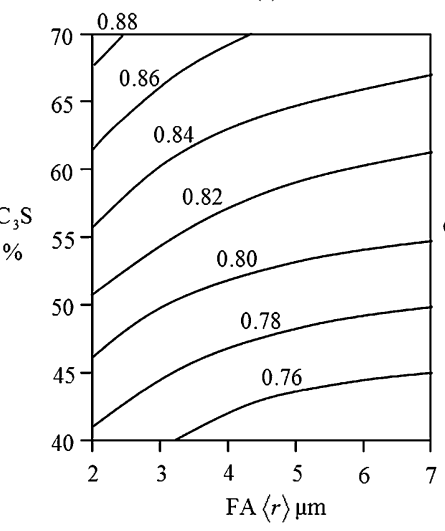

(d)

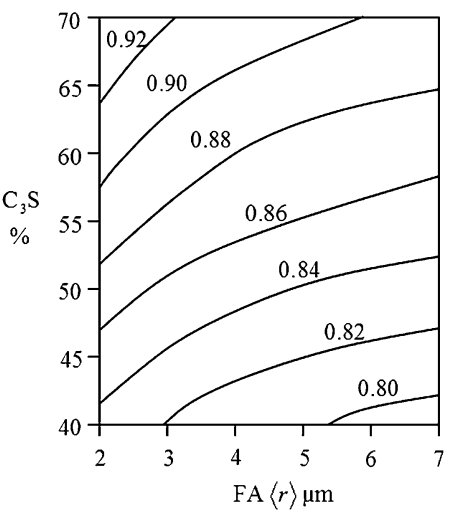

(e)

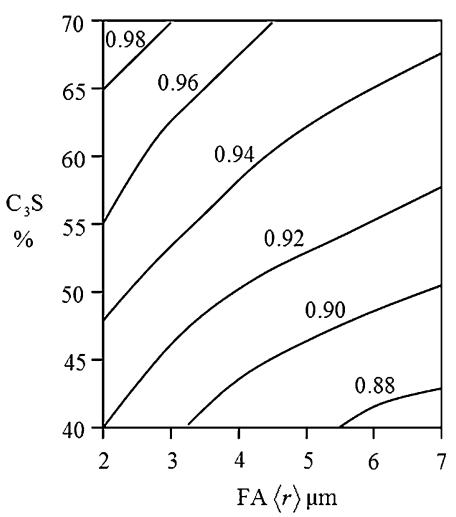

(f)

Fig. 4. Phase diagram of the reaction ratio of fly ash cement after (a) 7 days, (b) 14 days, (c) 28 days, (d) 56 days, (e) 91 days, and (f) 1 year. The horizontal axis and vertical axis represent the average particle size of fly ash and mass ratio of $\mathrm{C}_{3} \mathrm{~S}$ in $\mathrm{OPC}$, respectively.

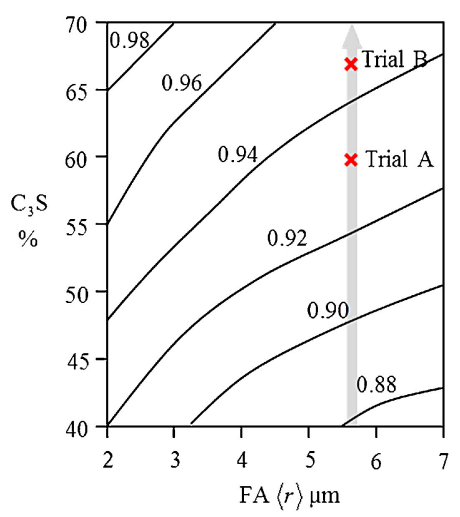

Fig. 5. Reaction ratio of fly ash cement after 1 year. The white arrow indicates the particle size of standard fly ash.

process. Controlling the quantity of $\mathrm{C}_{3} \mathrm{~S}$ in $\mathrm{OPC}$ is therefore a more practical approach for controlling the reaction ratio than preparing fly ash in a small particle size, as shown in Fig. 5.

\subsection{Measurement of hydration rates of fly ash cement used in OPC and HAC}

In an empirical trial evaluation, a general particle size distribution of fly ash was selected as shown in Fig. 6; the composition of this fly ash is listed in Table 3. The quantity of $\mathrm{C}_{3} \mathrm{~S}$ included in OPC was varied as listed in

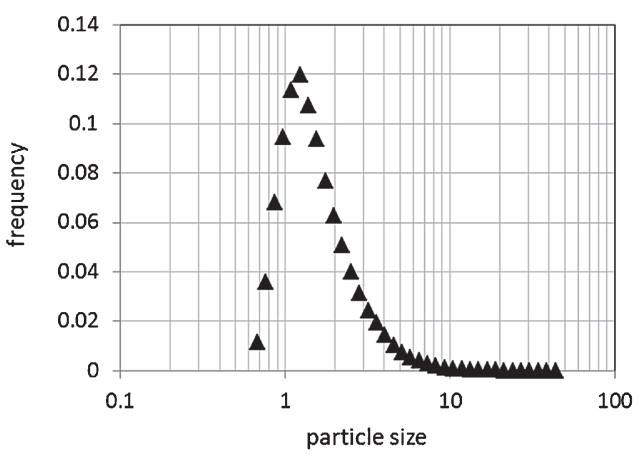

Fig. 6. Particle size distribution of the fly ash used in this experiment.

Table 3. Composition of fly ash used in the experiment

\begin{tabular}{ccccc}
\hline$\alpha$-Quartz & Mullite & Magnetite & $\mathrm{CaSO}_{4}$ & Glass phase \\
\hline 3.2 & 4.5 & 0.4 & 0.5 & 90.2 \\
\hline
\end{tabular}

Table 4. The compositions of the fly ash cement used in Trial A and Trial B were similar to the compositions of OPC and high alite cement (HAC), respectively. The particle size distributions in Trial A and Trial B are shown in Fig. 7. Table 5 shows the ratio of fly ash added to each sample in Trial A and Trial B, along with the sample names of these mixtures. The experimental method used to 
Table 4. Composition of samples with varying $\mathrm{C}_{3} \mathrm{~S}$ contents

\begin{tabular}{ccrrcc}
\hline & $\mathrm{C}_{3} \mathrm{~S}$ & $\mathrm{C}_{2} \mathrm{~S}$ & $\mathrm{C}_{3} \mathrm{~A}$ & $\mathrm{C}_{4} \mathrm{AF}$ & Free Lime \\
\hline Trial A & 59.3 & 15.6 & 10.3 & 10.6 & 0.1 \\
Trial B & 66.9 & 6.9 & 9.5 & 10.0 & 3.2 \\
\hline
\end{tabular}

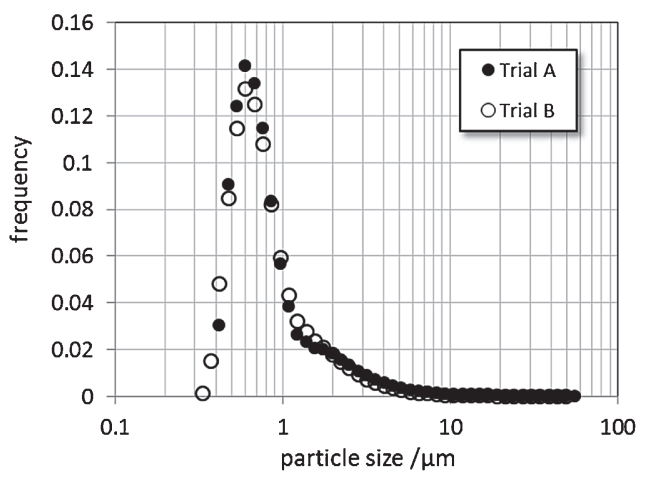

Fig. 7. Particle size distributions of the samples in Table 3.

Table 5. Mixing ratio of each sample type in Trial A-FA and Trial B-FA

\begin{tabular}{cc}
\hline Name & Fly ash ratio (mass \%) \\
\hline Trial A & $0 \%$ \\
Trial A + 10FA & $10 \%$ \\
Trial A + 20FA & $20 \%$ \\
Trial A + 30FA & $30 \%$ \\
Trial B & $0 \%$ \\
Trial B + 10FA & $10 \%$ \\
Trial B + 20FA & $20 \%$ \\
Trial B + 30FA & $30 \%$ \\
\hline
\end{tabular}

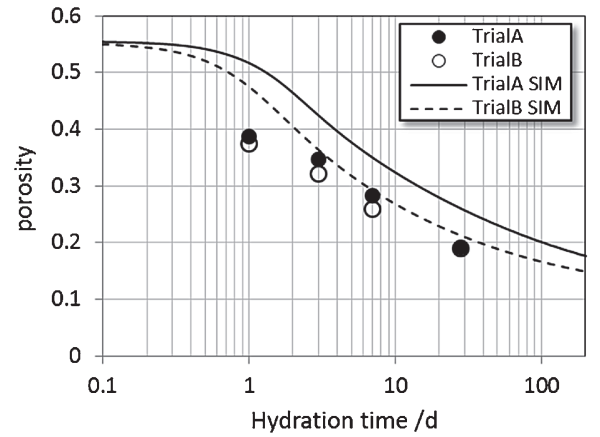

(a)

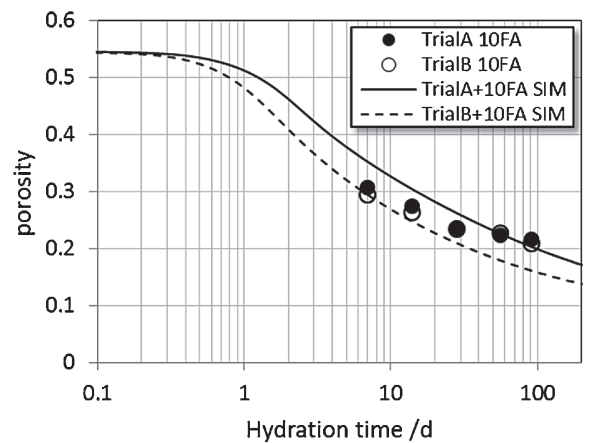

(b) measure the reaction ratio of the mixed system comprising OPC and fly ash was the same as that used in a previous study. ${ }^{2)}$

\subsection{Measurement of the porosity of fly ash cement used in OPC and HAC}

The number of pores in the various samples was measured, moreover, using a press fit mercury porosimeter. Figure 8 shows the time dependence of the porosity for the Trial A + fly ash system and the Trial B + fly ash system. The experimental data and simulation data for various samples are plotted in these figures. The simulation data were calculated using Eq. (8). When the quantity of $\mathrm{C}_{3} \mathrm{~S}$ in OPC increased, the reaction ratio increased, accompanied by a clear decrease in the porosity.

\section{Results and discussion}

The heat liberated from fly ash cement was measured using a conduction calorimeter; the experimental data (solid curve) and simulation data (dotted curve) for various samples are plotted in Figs. 9-16. Table 6 shows the fitting parameters of Eq. (4) used to simulate the experimental data in Figs. 9-16 using the particle size distribution, as shown by Eq. (9). Figure 17 shows the effective diffusion coefficients for all samples. The effective diffusion coefficient of the fly ash cement declined as the quantity of fly ash increased, as also observed in our previous study. ${ }^{3)}$ The effective diffusion coefficient $\left(D_{\mathrm{e}}\right)$ increased as the quantity of $\mathrm{C}_{3} \mathrm{~S}$ increased because $\mathrm{C}_{3} \mathrm{~S}$ contributes mainly to the hydration reaction. Figures 18(a)

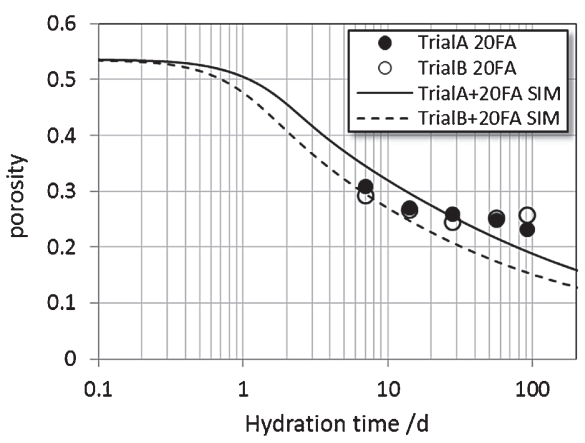

(c)

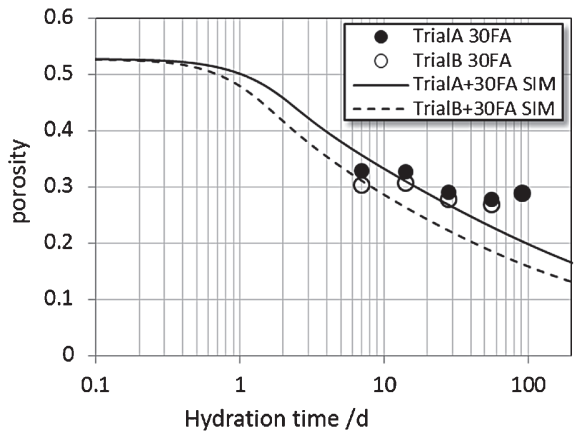

(d)

Fig. 8. Comparison of theoretical and experimental values based on the time dependence of porosity $(\Delta)$ for (a) Trial A and Trial B, (b) Trial A + fly ash $10 \%$ and Trial B + fly ash $10 \%$, (c) Trial A + fly ash $20 \%$ and Trial B + fly ash $20 \%$, and (d) Trial A + fly ash $30 \%$ and Trial B + fly ash $30 \%$. 


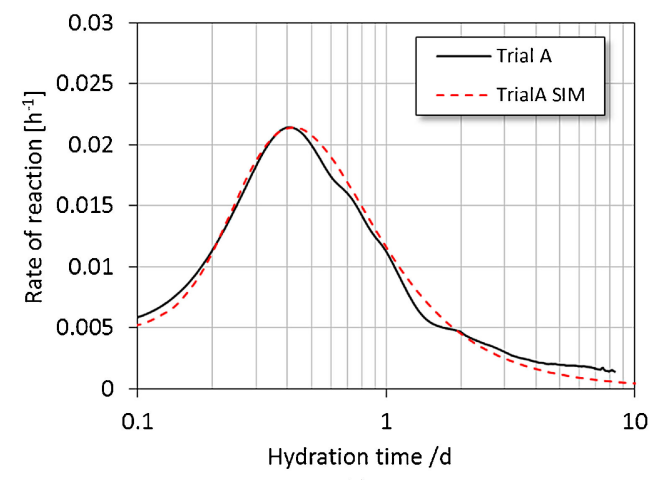

(a)

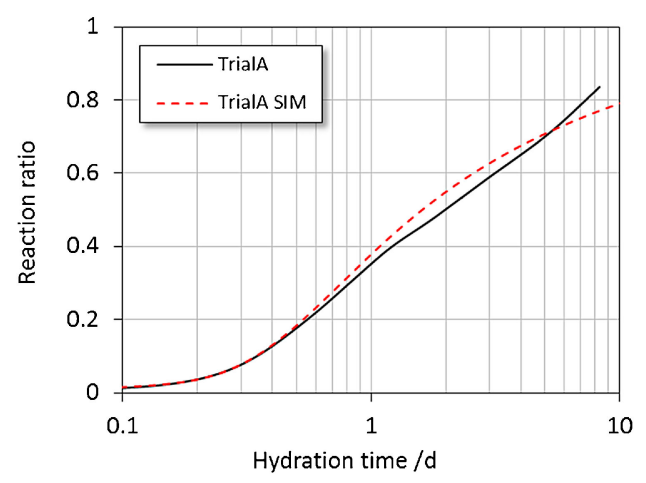

(b)

Fig. 9. (a) Comparison of experimental data and simulation results for the rate of reaction for Trial A. (b) Comparison of experimental data and simulation results for the reaction ratio for Trial A.

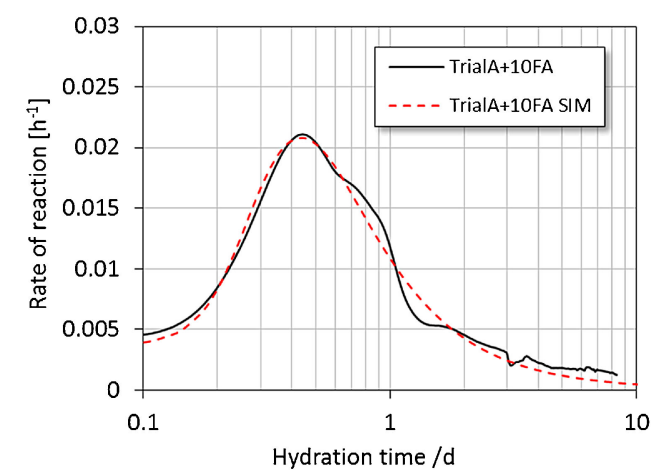

(a)

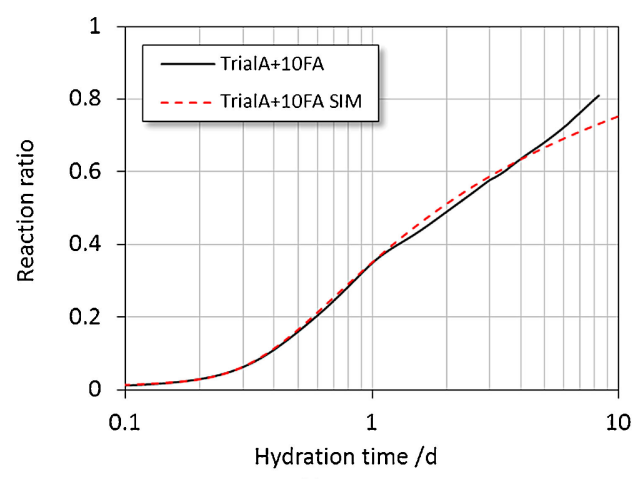

(b)

Fig. 10. (a) Comparison of experimental data and simulation results for the rate of reaction for Trial $\mathrm{A}+$ fly ash $10 \%$. (b) Comparison of experimental data and simulation results for the reaction ratio for Trial $\mathrm{A}+$ fly ash $10 \%$.

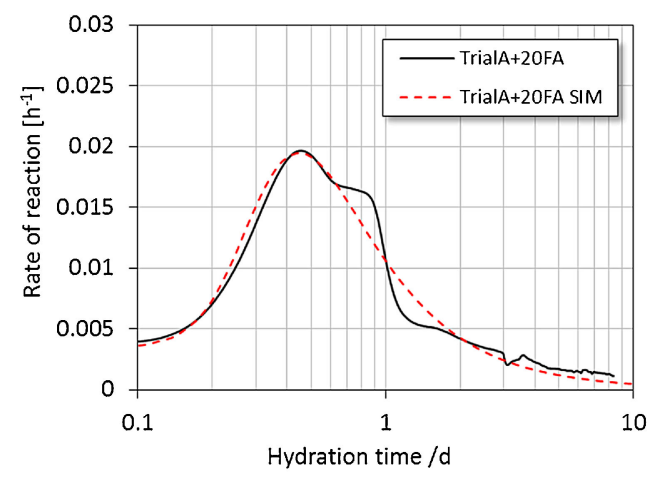

(a)

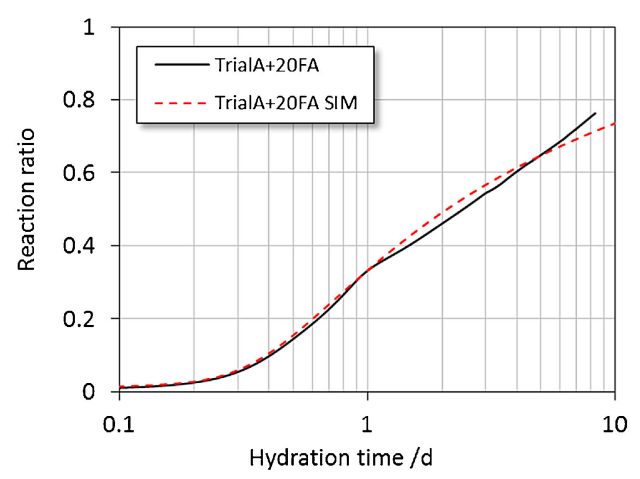

(b)

Fig. 11. (a) Comparison of experimental data and simulation results for the rate of reaction for Trial $\mathrm{A}+$ fly ash $20 \%$. (b) Comparison of experimental data and simulation results for the reaction ratio for Trial A + fly ash $20 \%$.

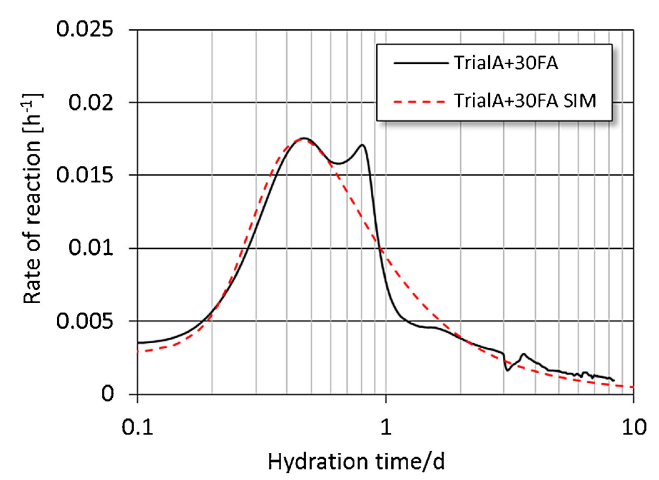

(a)

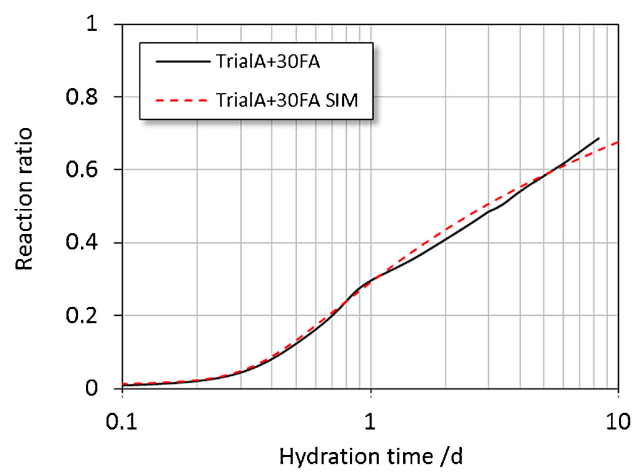

(b)

Fig. 12. (a) Comparison of experimental data and simulation results for the rate of reaction for Trial A + fly ash $30 \%$. (b) Comparison of experimental data and simulation results for the reaction ratio for Trial A + fly ash $30 \%$. 


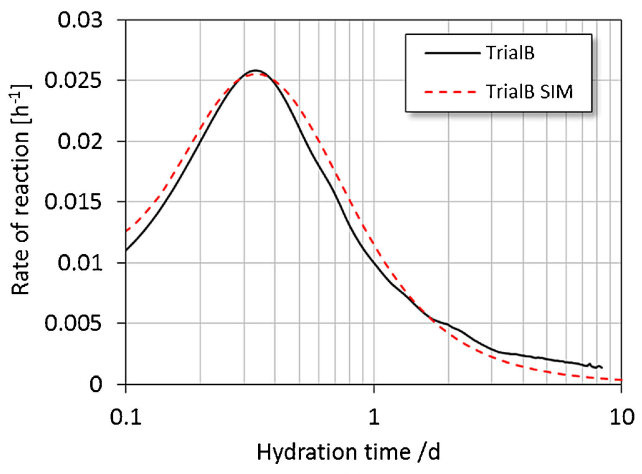

(a)

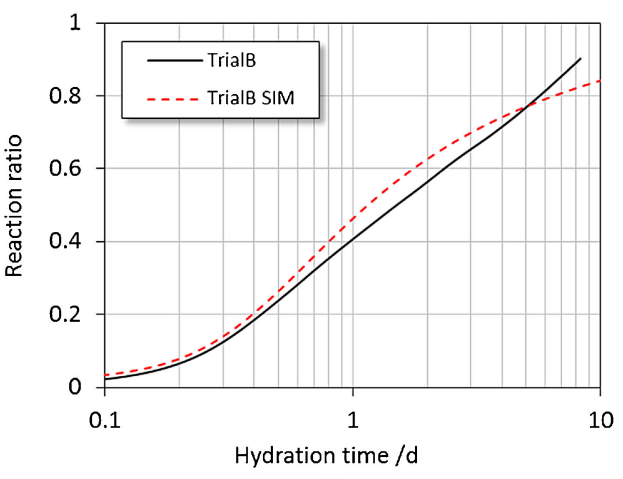

(b)

Fig. 13. (a) Comparison of experimental data and simulation results for the rate of reaction for Trial B. (b) Comparison of experimental data and simulation results for the reaction ratio for Trial B.

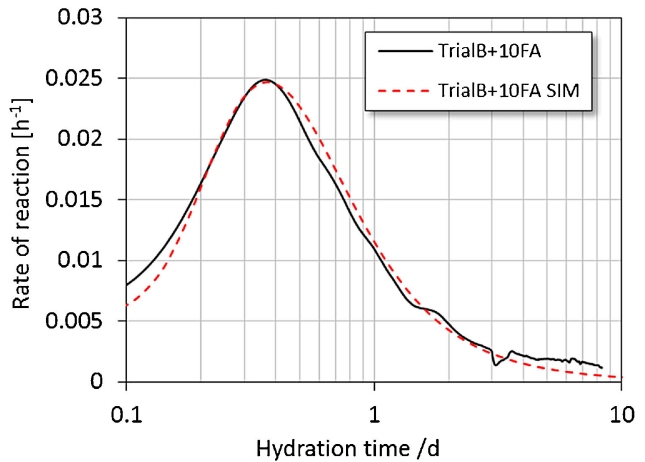

(a)

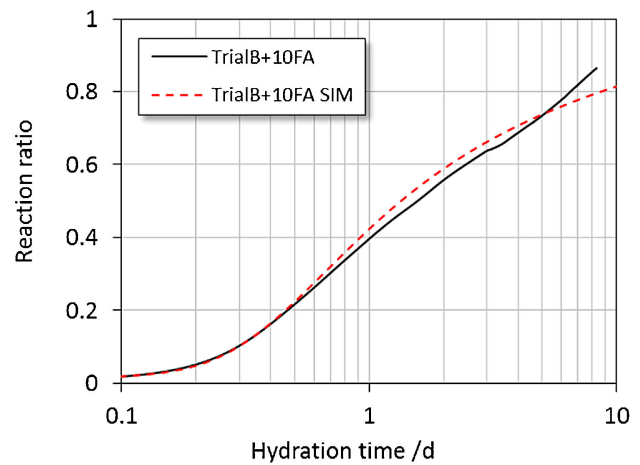

(b)

Fig. 14. (a) Comparison of experimental data and simulation results for the rate of reaction for Trial $\mathrm{B}+$ fly ash $10 \%$. (b) Comparison of experimental data and simulation results for the reaction ratio for Trial B + fly ash $10 \%$.

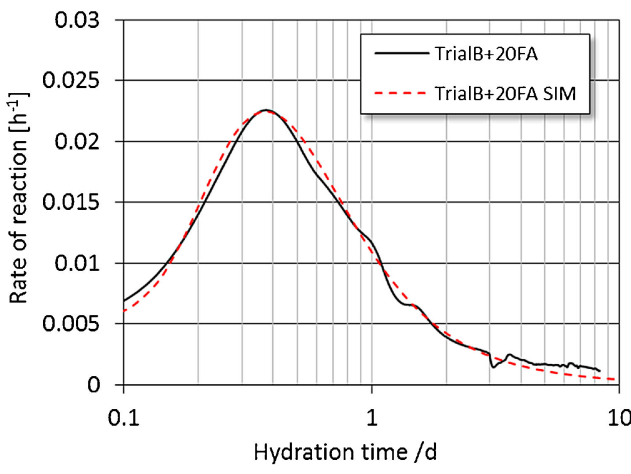

(a)

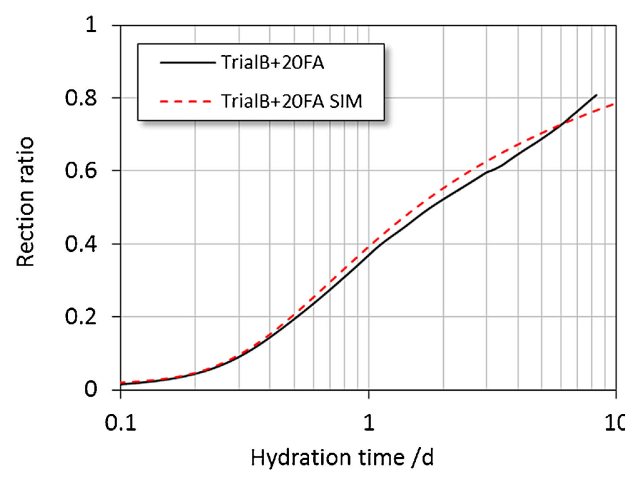

(b)

Fig. 15. (a) Comparison of experimental data and simulation results for the rate of reaction for Trial B + fly ash $20 \%$. (b) Comparison of experimental data and simulation results for the reaction ratio for Trial B + fly ash $20 \%$.

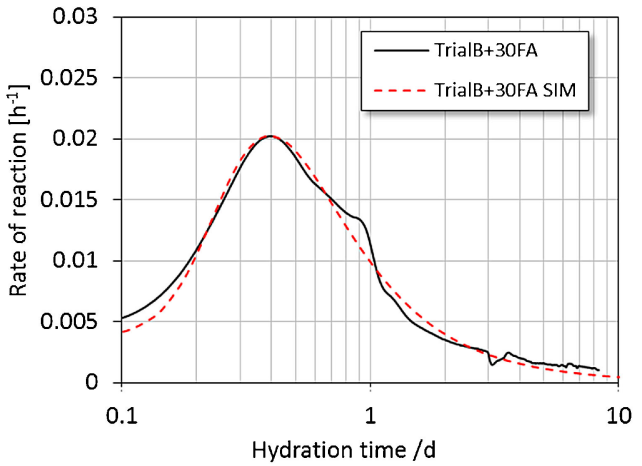

(a)

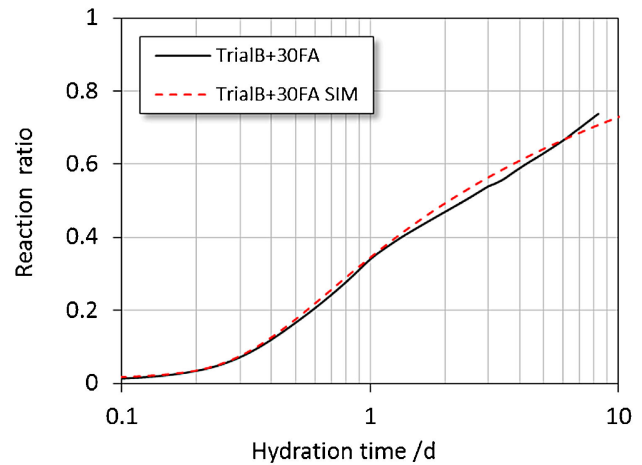

(b)

Fig. 16. (a) Comparison of experimental data and simulation results for the rate of reaction for Trial B + fly ash $30 \%$. (b) Comparison of experimental data and simulation results for the reaction ratio for Trial B + fly ash $30 \%$. 
Table 6. Fitting parameters in Eq. (1) determined by simulating the rate of reaction for each sample

\begin{tabular}{ccccc}
\hline Name & $k_{r}[\mathrm{~cm} / \mathrm{h}]$ & $B_{\mathrm{d}}[\mathrm{cm} / \mathrm{h}]$ & $C_{\mathrm{d}}[\mathrm{cm} / \mathrm{h}]$ & $D_{\mathrm{e}}\left[\mathrm{cm}^{2} / \mathrm{h}\right]$ \\
\hline Trial A & $6.2 \times 10^{-7}$ & $1.0 \times 10^{-9}$ & $2.0 \times 10^{-4}$ & $1.2 \times 10^{-11}$ \\
Trial A + 10FA & $6.7 \times 10^{-7}$ & $6.5 \times 10^{-10}$ & $2.0 \times 10^{-4}$ & $8.0 \times 10^{-12}$ \\
Trial A + 20FA & $6.5 \times 10^{-7}$ & $6.0 \times 10^{-10}$ & $2.0 \times 10^{-4}$ & $7.0 \times 10^{-12}$ \\
Trial A + 30FA & $6.7 \times 10^{-7}$ & $4.5 \times 10^{-10}$ & $2.0 \times 10^{-4}$ & $4.0 \times 10^{-12}$ \\
Trial B & $7.2 \times 10^{-7}$ & $5.0 \times 10^{-9}$ & $1.5 \times 10^{-4}$ & $2.1 \times 10^{-11}$ \\
Trial B + 10FA & $7.1 \times 10^{-7}$ & $1.0 \times 10^{-9}$ & $2.4 \times 10^{-4}$ & $1.5 \times 10^{-11}$ \\
Trial B + 20FA & $6.6 \times 10^{-7}$ & $1.0 \times 10^{-9}$ & $2.4 \times 10^{-4}$ & $1.1 \times 10^{-11}$ \\
Trial B + 30FA & $6.7 \times 10^{-7}$ & $6.0 \times 10^{-10}$ & $2.4 \times 10^{-4}$ & $6.0 \times 10^{-12}$ \\
\hline
\end{tabular}

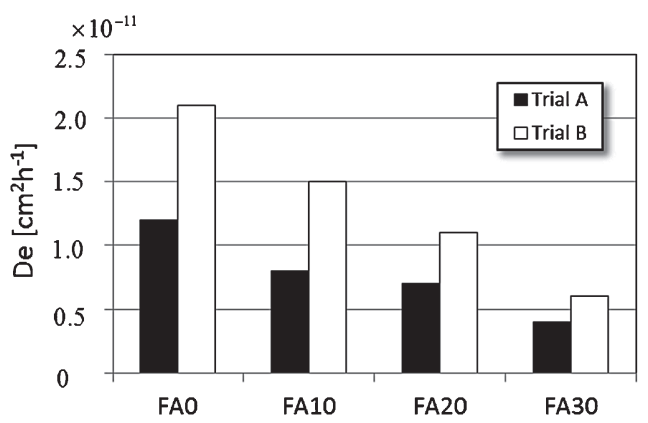

Fig. 17. Fitting parameters for the effective diffusion of various fly ash cements in Table 6.

and 18(b) show a summary of the reaction ratios for the Trial A series and Trial B series simulations, respectively. Figure 18(c) shows a comparison of the reaction ratios between Trial A and Trial B + fly ash $20 \%$. The reaction ratio of Trial B + fly ash $20 \%$ is nearly identical to that of Trial A.

\section{Conclusion}

Simulation of the reaction ratio of fly ash cement, taking into account various parameters, including the $\mathrm{C}_{3} \mathrm{~S}$ quantity and fly ash particle size based on the experimental data of Miyahara, demonstrated that the reaction ratio of the fly ash cement was almost independent of the fly ash particle size seven days after the initial reaction. Therefore, the fly ash particle size does not have to be considered in discussions of the fly ash cement strength in the initial stage of the reaction. Twenty-eight days after the initial reaction, however, the fly ash particle size dependence of the cement reaction rate on the fly ash particle size becomes remarkable, and this effect becomes extremely pronounced by one year after the initial reaction. However, Controlling the particle size of fly ash added to fly ash cement is not inexpedient, however, in industrial mass production. Thus, instead of manipulating the reaction ratio by controlling the particle size of fly ash added to cement, evaluation of the reaction ratio and porosity of fly ash cement with various quantities of $\mathrm{C}_{3} \mathrm{~S}$ in OPC, demonstrated that fly ash cement containing approximately $20 \%$ fly ash in high a-lite cement exhibited characteristics similar to those of OPC alone.

Acknowledgement This research was partially supported by the Collaborative Research Division Program on Future

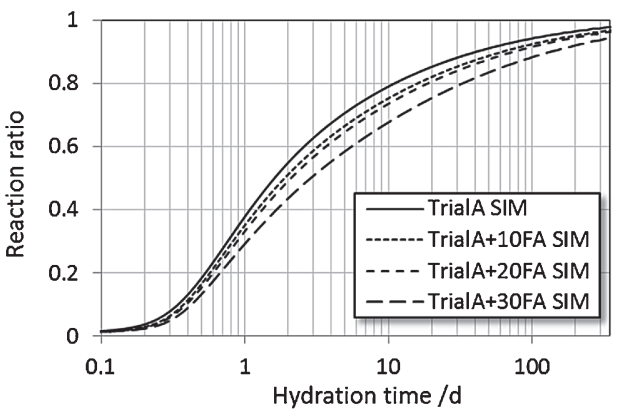

(a)

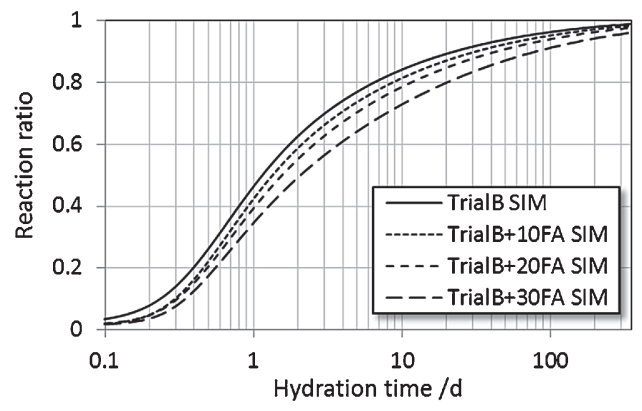

(b)

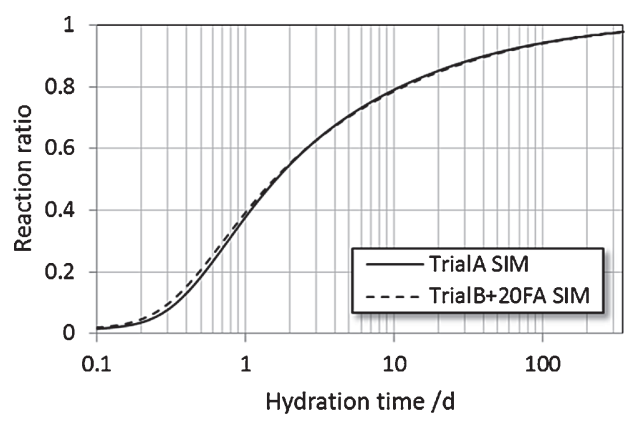

(c)

Fig. 18. Comparison of the simulated values of the reaction ratios for the (a) Trial A + fly ash and (b) Trial B + fly ash series experiments. (c) Comparison between the Trial A and Trial B + fly ash $20 \%$ experiments.

Cementitious Materials in Tokyo Institute of Technology, and the authors wish to express their gratitude to the members concerned.

\section{References}

1) Concrete Committee of Japan Society of Civil Engineer State-of-the-art report for utilization of by products (in Japan), Concrete Library, Japan Society of Civil Engineers, 132 p.325 (2009).

2) E. Sakai, S. Miyahara, S. Ohsawa, S.-H. Lee and M. Daimon, Cement Concr. Res., 35, 1135-1140 (2005).

3) Y. Aikawa, S. Miyahara, D. Atarashi, N. Siribudhaiwan and E. Sakai, J. Ceram. Soc. Jpn., 123, 1073-1079 (2015).

4) F. C. Lian, Y. Zhuge and S. Beecham, Construct. Build. Mater., 25, 4294-4298 (2011).

5) F. Tomosawa, Cement gijyutu nenpo (Cement technology annual report), 28, 53-57 (1974) [in Japanese].

6) Y. Aikawa, D. Atarashi, T. Nakazawa and E. Sakai, J. Ceram. Soc. Jpn., 122, 810-816 (2014). 